\title{
Comparative Studies of the Physicochemical Properties of Moringa oleifera (Nigeria), Moringa oleifera (Kenya) and Moringa oleifera (India)
}

Bale $\mathrm{AT}^{1 *}$, Olubuade $\mathrm{FE}^{1}$, Ogundele $\mathrm{DT}^{1}$, Olayemi VT' ${ }^{1}$, Jimoh $\mathrm{AA}^{2}$ and Musa $\mathrm{RT}^{2}$

${ }^{1}$ Department of Chemistry, Kwara State University, Malete, Nigeria

${ }^{2}$ Department of Chemistry, Al-hikmah University, Ilorin, Kwara State, Nigeria

\begin{abstract}
The oil from Moringa oleifera seeds obtained from Afon in Asa Local Government Area of Kwara State, Nigeria, was extracted using $n$-hexane. The oil yield determined experimentally was $26.2 \%$. The oil concentration was compared with those reported by [1,2]. Some physicochemical properties like the density, specific gravity, refractive index, $\mathrm{pH}$, viscosity, acid value, peroxide value, saponification value, iodine value and FFA were determined. The results obtained were compared against previously reported data.
\end{abstract}

Keywords: Moringa oleifera; n-Hexane; Fatty acids; Physicochemical properties

\section{Introduction}

The Moringaceae is a single genius family of oil seed tree with 14 known species. Moringa oleifera is the most widely known and utilized. Moringa oil comes from the seeds of Moringa oleifera tree, a fast growing leafy tree species native to the Himalayas. Moringa oleifera contain between 33 and $41 \% \mathrm{w} / \mathrm{w}$ of vegetable oil.

The oil extracted from Moringa is known as Ben oil and reportedly contains $70 \%$ of oleic acid, an 18-carbon long monounsaturated fatty acid. Because the oleic acid has good oxidative stability when compared with polyunsaturated fatty acids, it has found use in the food industry, as it allows for longer storage and high-temperature frying processing. Another potential use of Moringa oil is as biodiesel feedstock. It also has uses in medicine and water treatment [3].

In this study, experimental results of solvent soxhlet extraction using $\mathrm{n}$-hexane are reported. Solvent extraction has been reported by both Tsaknis et al. [1,2] and Palafox et al. [3]. Experimental results obtained from this research work will be compared with those obtained by the two scientists mentioned above.

\section{Materials and Methods}

\section{Material and Sample Preparation}

The Moringa oleifera seeds used were obtained from Afon in Asa Local Government Area of Kwara State, Nigeria. The pods were removed from the seeds to get the nuts inside. The nuts were then sundried in the open floor for a certain period of time to reduce the moisture content of the seeds and also for easy detachment of the seeds from the nuts.

After the seed has been separated from the nuts, they were dried in an oven at $105^{\circ} \mathrm{C}$ for 8 hours until a constant weight was obtained. The dried seeds were later ground into powder (approximately $2 \mathrm{~mm}$ particle size) using a hand-operated mortar.

\section{Soxhlet extraction method}

The Franz Von soxhlet extractor described by the AOAC (Association of Official Analytical Chemists) method was used for the extraction. The solvent used for the extraction was n-hexane.

About $100 \mathrm{~g}$ of the ground Moringa oleifera seeds were loaded into the soxhlet apparatus set. The extraction was carried out at $68^{\circ} \mathrm{C}$ (boiling temperature of $\mathrm{n}$-hexane) for 10 hours.
Supernatant solution was collected which was the mixture of the extracted oil and the n-hexane. The suspension present in the solution was removed by filtration. After filtration, the solvent was eliminated in a rotavapor and the yield was calculated as grams of oil extract divided by grams of total seeds used.

\section{Physicochemical analysis}

Chemical analysis: The chemical properties such as iodine value (IV), saponification value (SV), acid value (AV), and peroxide value (PV) were determined by the method described by AOAC method (Association of Official Analytical Chemists).

Physical analysis: The physical properties such as density $(\rho)$, refractive index, and viscosity $(\gamma)$ of the oil extracted were also determined.

\section{Results and Discussion}

\section{Experimental data}

Yield was defined as grams of extracted oil divided by grams of total seeds used. The results obtained for the solvent extraction of Moringa oil including the physicochemical properties is presented in the table below. The oil content of Moringa oleifera (Nigeria), its physical and chemical properties are shown in Table 1 . The oil content and the physicochemical properties were compared with the results obtained by Tsaknis et al. [1,2] in Table 2 .

The oil content of the Moringa oleifera (Nigeria) was found to be relatively low compared with Tsaknis et al. [1,2], this may be due to difference in locations and moringa oil genotypes. The seed oil content depends on the genotype but it is also affected by the environmental conditions, cultural practices and time of harvesting [4].

The results of some of the physicochemical properties like the density, refractive index, viscosity and saponification value obtained

*Corresponding author: Bale AT, Department of Chemistry, Kwara State University Malete, Nigeria, Tel: +2348060445810; E-mail: bayobale@gmail.com

Received April 20, 2015; Accepted June 11, 2015; Published June 16, 2015

Citation: Bale AT, Olubuade FE, Ogundele DT, Olayemi VT, Jimoh AA, et al (2015) Comparative Studies of the Physicochemical Properties of Moringa oleifera (Nigeria) Moringa oleifera (Kenya) and Moringa oleifera (India). Nat Prod Chem Res 3: 178 doi:10.4172/2329-6836.1000178

Copyright: (c) 2015 Bale AT, et al. This is an open-access article distributed under the terms of the Creative Commons Attribution License, which permits unrestricted use, distribution, and reproduction in any medium, provided the original author and source are credited. 


\begin{tabular}{|c|c|}
\hline Parameters & Value \\
\hline Oil content (g oil/100 g seed) & 26.2 \\
\hline Density (mg/mL) & 0.884 \\
\hline Specific gravity & 0.8885 \\
\hline Refractive index & 1.49 \\
\hline Viscosity $\left(\mathrm{cm}^{3} / \mathrm{sec}\right)$ & 49.96 \\
\hline $\mathrm{pH}$ & 6.52 \\
\hline FFA (Free fatty acids)\% & 3.55 \\
\hline Saponification value $(\mathrm{mg} \mathrm{KOH} / \mathrm{g})$ & 180.31 \\
\hline lodine value $\left(\mathrm{g} \mathrm{I}_{2} / 100 \mathrm{~g}\right)$ & 55.02 \\
\hline Acid value $(\mathrm{mg} \mathrm{KOH} / \mathrm{g})$ & 7.09 \\
\hline Peroxide value $(\mathrm{mg} \mathrm{KOH} / \mathrm{g})$ & 15.98 \\
\hline
\end{tabular}

Table 1: Characteristics of the Moringa oleifera seed oil.

\begin{tabular}{|l|l|l|l|}
\hline Moringa oleifera seed oil (Nigeria) & & $\begin{array}{l}\text { Tsaknis et al. } \\
(\mathbf{1 9 9 9 )} \text { (Kenya) }\end{array}$ & $\begin{array}{l}\text { Tsaknis et al. } \\
(\mathbf{2 0 0 2}) \text { (India) }\end{array}$ \\
\hline Parameters & Value & Value & Value \\
\hline Oil content $(\mathrm{g}$ oil/100 g seed) & 26.2 & 35.7 & 38.3 \\
\hline Density $(\mathrm{mg} / \mathrm{mL})$ & 0.884 & 0.8809 & 0.899 \\
\hline Specific gravity & 0.8885 & $\mathrm{~N} / \mathrm{A}$ & $\mathrm{N} / \mathrm{A}$ \\
\hline Refractive index & 1.49 & 1.4549 & 1.457 \\
\hline Viscosity $\left(\mathrm{cm}^{3} / \mathrm{sec}\right)$ & 49.96 & 57 & 45.05 \\
\hline pH & 6.52 & $\mathrm{~N} / \mathrm{A}$ & $\mathrm{N} / \mathrm{A}$ \\
\hline FFA $($ Free fatty acids)\% & 3.55 & 0.85 & 1.12 \\
\hline Saponification value $(\mathrm{mg} \mathrm{KOH} / \mathrm{g})$ & 180.31 & 178.11 & 188.36 \\
\hline lodine value $(\mathrm{g} \mathrm{I} / 100 \mathrm{~g})$ & 55.02 & 66.83 & 65.58 \\
\hline Acid value $(\mathrm{mg} \mathrm{KOH} / \mathrm{g})$ & 7.09 & N/A & N/A \\
\hline Peroxide value $(\mathrm{mg} \mathrm{KOH} / \mathrm{g})$ & 15.98 & N/A & N/A \\
\hline
\end{tabular}

Note: N/A indicates not available.

Table 2: Characteristics of the Moringa oleifera seed oil compared with Tsaknis et al. [1,2].

in the present research work was found to be relatively close to those reported by Tsaknis et al. [1,2].

The difference in the iodine value and other properties may be due to the quality of the oil and unfavourable environmental conditions.

\section{Conclusion}

In this present work, the extraction and characterization of Moringa oleifera seed obtained fron Afon in Asa Local Government Area, Kwara State. Nigeria have been carried out. Although in this study, the oil yield was low, Moringa seeds still remain a good source for oil rich in oleic acid that could be converted to biofuel. It is a potential candidate for biodiesel production.

The Moringa oleifera seed oil according to Tsaknis et al. [2] could be utilized successfully as a source of edible oil for human consumption. It has been found to contain high monounsaturated fatty acids and might be an acceptable substitute for highly monounsaturated oils such as olive oil in diets.

Moringa oleifera is a tree found to thrive well even in poor soil and is not really affected by drought $[5,6]$ and can be easily grown in developing countries like Nigeria. The extraction of oil from its seeds could be of high economic benefit to the communities where the tree is cultivated.

\section{References}

1. Tsaknis J, Spiliotis V, Lalas S, Gergis V, Dourtoglou V (1999) Quality changes of Moringa oleifera, variety Mbololo of Kenya seed oil during frying. J Agric Food Chem 47: 4495-4499.

2. Tsaknis J, Lalas S (2002) Characterization of Moringa oleifera Seed Oil Variety "Periyakulam 1". J Food Compost Anal 15: 65-77.

3. Palafox JO, Navarrete A, Sacramento-Rivero JC, Rubio-Atoche C, Escoffie, PA, et al. (2012) Extraction and Characterization of Oil from Moringa oleifera Using Supercritical $\mathrm{CO} 2$ and Traditional Solvents. American Journal of Analytical Chemistry 3: 946-949.

4. Koutroubas SD, Papakosta DK, Doitsinis A (1999) Adaptation and yielding ability of castor plant (Ricinus communis L.) genotypes in a Mediterranean climate. Eur J Agron 11: 227-237.

5. Sengupta A, Gupta MP (1970) Studies on seed fat composition of Moringaceae family. Eur J Lipid Sci Technol 72: 6-10.

6. Morton JF (1991) The Horseradish tree, Moringa pterigosperma (Moringaceae)-a boon to arid lands? Econ Bot 45: 318-333. 